\title{
Analisis Volatilitas Return Saham PT Antam (Persero) Tbk dan PT Adaro Energy Tbk dengan Garch, Egarch dan GJR
}

\author{
Yasir Maulana \\ Program Studi Manajemen Fakultas Ekonomi Universitas Kuningan, Indonesia \\ *Email korenpondensi: yasir@uniku.ac.id
}

\begin{abstract}
An extraordinary event that causes shock can affect volatility which causes asymmetric variance and error or commonly called asimetric shock / effect. This paper aims to analyze the volatility of stock returns of PT ANTAM (Persero) Tbk and PT Adaro Energy Tbk in the period of 2008 to 2016. The research results show that ANTM and ADRO have a GARCH effect and also have a leverage effect where the optimal model is found in the GJR model $(0,1,1)$ for ANTM and GJR $(1,1,1)$ for ADRO. Forecasting results shows that ADRO has higher volatility but in a relatively low percentage of volatility about 0.001 while ANTM have a tendency to decrease volatility with a fairly large percentage of volatility about 0.0025 .
\end{abstract}

\section{Keywords: EGARCH, GARCH, GJR, Volatility}

Saran sitasi: Maulana, Y. (2020). Analisis Volatilitas Return Saham PT Antam (Persero) Tbk dan PT Adaro Energy Tbk dengan Garch, Egarch dan GJR. Jurnal Akuntansi dan Pajak, 20(2), 192-195. doi:http://dx.doi.org/10.29040/jap.v20i2.859

DOI: http://dx.doi.org/10.29040/jap.v20i2.859

\section{Pendahuluan}

Penelitian ini bertujuan untuk menganalisis pergerakan volatilitas return saham PT. ANTAM (Persero) Tbk. (ANTM) dan PT. Adaro Energy Tbk. (ADRO). Volatilitas yang tinggi menyebabkan adanya variance dan error yang tidak konstan, sehingga menimbulkan adanya efek heterokedastisitas. Adanya suatu kejadian yang luar biasa menyebabkan guncangan atau shock dapat mempengaruhi volatilitas menyebabkan variance dan error yang asimetri biasa disebut asimetric shock/ effect. Untuk itu peneliti memilih data saham ANTM dan ADRO dengan periode dari tanggal 16 Juli 2008 sampai tanggal 6 Mei 2014.

Latar belakang pemilihan periodisasi data dari tahun 2008 adalah karena diasumsikan di tahun 2008 terdapat shock yang disebabkan oleh krisis global 2008, yang diharapkan bahwa saham ini mempunyai efek yang signifikan dalam pemodelan GARCH, EGARCH dan GJR. Kedua, alasan memilih data saham di industri pertambangan adalah karena selama periode 2008 dan 2016 industri tersebut sedang mengalami fluktuasi kenaikan dan penurunan kinerja yang diduga bahwa kedua saham ini mempunyai efek volatilitas yang tinggi, yang ketiga adalah pada tahun 2014 - 2016 industri pertambangan mengalami kinerja yang buruk yang menyebabkan menurunnya harga saham pada jenis/ sektor industri ini. Ketika harga saham sedang rendah inilah diharapkan investor dapat masuk berinvestasi dalam saham tersebut dengan memperhatikan dan memahami analisis volatilitas ini dalam memprediksi risiko yang mungkin terjadi.

\section{Metode Penelitian}

Metode pemodelan yang dapat digunakan untuk mengatasi gejala heterogenitas varians adalah metode Autoregressive Conditional Heteroscedasticity (ARCH) sebuah metode dikembangkan oleh Engle tahun 1982. Pergerakan varians pada model ARCH dipengaruhi oleh sejumlah T random data sebelumnya. Model tersebut digeneralisasikan oleh Bollerslev pada tahun 1986 untuk mengatasi orde yang terlalu tinggi pada model ARCH serta terjadinya pelanggaran terhadap nonnegativity constraints, yang sebut dengan metode Generalized ARCH (GARCH). Pada model ini, perubahan variansinya dipengaruhi oleh data sebelumnya dan variansi dari data sebelumnya. Model ARCH maupun GARCH mengasumsikan bahwa error yang positif dan error yang memiliki 


\section{Jurnal Akuntansi dan Pajak, 20(02), 2019, 198}

nilai negatif akan berpengaruh sama terhadap volatilitasnya.

Namun faktanya, asumsi tersebut seringkali dilanggar, karena umumnya data time series justru menunjukkan fenomena ketidaksimetrisan antara nilai error positif dan error negatif terhadap volatilitasnya. Pada data indeks dari harga saham jika nilai error kurang dari nol, berarti nilai indeks harga saham hasil estimasi akan lebih besar dari harga yang asli, dan ini merupakan kondisi yang buruk yang disebut bad news. Sebaliknya, ketika nilai error lebih besar dari nol berarti nilai indeks harga saham lebih besar daripada harga estimasinya sehingga menghasilkan keuntungan yang disebut good news.

Contoh yang sering terjadi adalah data return saham, dimana kondisi bad news dan good news akan memberikan pengaruh asimetris terhadap volatilitasnya, hal ini yang disebut dengan leverage effect. Metode yang dapat digunakan untuk menghadapi data dengan perubahan yang asimetrik adalah metode Exponential GARCH dan T-GARCH (GJR). Perbedaan keduanya adalah EGARCH memasukan faktor eksponensial dalam persamaannya, dan GJR/TGARCH hanya mencakup efek informasi saja.

\section{Hasil dan Pembahasan}

Pada harga kedua saham, dapat kita lihat bahwa di akhir tahun 2008 harga saham turun sangat signifikan yang mungkin dikarenakan efek dari krisis global tahun 2008 di Amerika Serikat, kemudian sempat menguat sampai tahun 2011 dan kemudian harga jatuh lagi sampai awal tahun 2016 yang kemungkinan disebabkan oleh penurunan harga minyak dunia. Dari segi volatilitas return dapat kita lihat bahwa ADRO lebih volatile dibandingkan ANTM. Fluktuasi dapat kita lihat berada di sekitar tahun 2008, 2012, 2014 dan 2016 (gambar 1.)
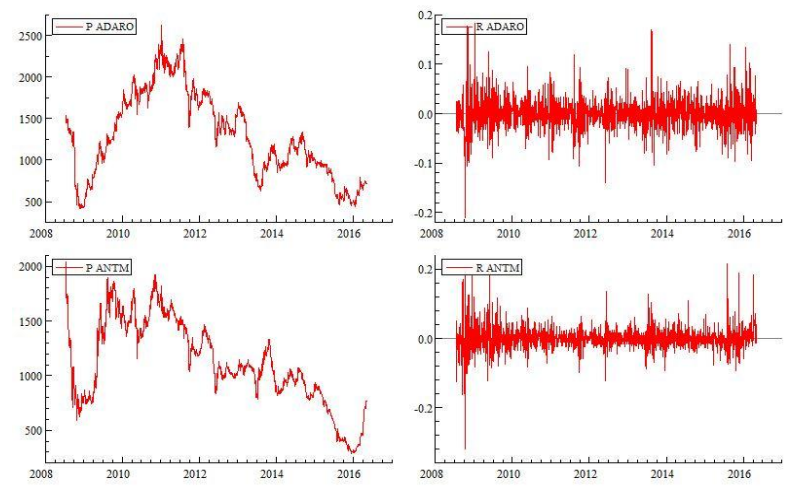

Gambar 1.

Volatilitas harga dan return saham ANTM dan ADRO a. Uji GARCH

Berdasarkan hasil uji GARCH $(1,1)$ menggunakan Oxmetrics untuk 1965 observasi, didapat hasil uji untuk ANTM adalah sebagai berikut:

Tabel 1. Hasil Uji GARCH ANTM

\begin{tabular}{|c|c|c|c|c|}
\hline Model & Coefficient & Std. Error & t-value & t-prob \\
\hline ARCH (Alpha1) & 0.104556 & 0.024218 & 4.317 & 0.0000 \\
\hline GARCH (Beta1) & 0.884896 & 0.020386 & 43.41 & 0.0000 \\
\hline
\end{tabular}

Hasil uji GARCH ANTM menunjukan t-prob $\alpha 1$ sebesar 0.0000 dimana nilai ini berada dibawah nilai signifikansi 0.05 maka $\alpha 1$ atau $\mathrm{ARCH}$ signifikan terhadap $\sigma 2$ dan $\mathrm{t}$-prob $\beta 1$ sebesar 0.0000 dimana nilai ini berada dibawah nilai signifikansi 0.05 maka $\beta 1$ atau GARCH signifikan terhadap $\sigma 2$.

Berdasarkan hasil uji GARCH $(1,1)$ ADRO menggunakan Oxmetrics untuk 1961 observasi, didapat hasil uji untuk ADRO adalah sebagai berikut:

Tabel 2.

Hasil Uji GARCH ADRO

\begin{tabular}{|c|c|c|c|c|}
\hline Model & Coefficient & Std.Error & t-value & t-prob \\
\hline ARCH (Alpha1) & 0.110317 & 0.034661 & 3.183 & 0.0015 \\
\hline GARCH (Beta1) & 0.861480 & 0.044462 & 19.38 & 0.0000 \\
\hline
\end{tabular}

Hasil uji GARCH ADRO menunjukan t-prob $\alpha 1$ sebesar 0.0015 dimana nilai ini berada dibawah nilai signifikansi 0.05 maka $\alpha 1$ atau $\mathrm{ARCH}$ signifikan terhadap $\sigma 2$ dan t-prob $\beta 1$ sebesar 0.0000 dimana nilai ini berada dibawah nilai signifikansi 0.05 maka $\beta 1$ atau GARCH signifikan terhadap $\sigma 2$.

Dari hasil yang yang diperoleh kedua perusahaan sama - sama memiliki GARCH $(1,1)$ effect yang signifikan. Setelah itu penulis ingin melihat apakah kedua saham ini mempunyai leverage efect, maka dari itu kemudian dilakukan langkah memodelkan ke model EGARCH dan GJR lalu membandingkan mana diantara ketiga model ini yang paling sesuai dijadikan model utama.

\section{b. Uji EGARCH}

Berdasarkan hasil uji EGARCH $(1,1)$ menggunakan Oxmetrics untuk 1965 observasi, didapat hasil uji untuk ANTM adalah sebagai berikut:

Tabel 3.

Hasil Uji EGARCH ANTM

\begin{tabular}{|c|c|c|c|c|}
\hline Model & Coefficient & Std. Error & t-value & t-prob \\
\hline ARCH (Alpha1) & 0.393438 & 0.65892 & 0.5971 & 0.5505 \\
\hline GARCH (Beta1) & 0.962478 & 0.012102 & 79.53 & 0.0000 \\
\hline EGARCH (Theta1) & -0.034058 & 0.019154 & -1.778 & 0.0755 \\
\hline EGARCH (Theta2) & 0.175278 & 0.086052 & 2.037 & 0.0418 \\
\hline
\end{tabular}


Jurnal Akuntansi dan Pajak, 20(02), 2019, 199

Berdasarkan hasil uji EGARCH $(1,1)$ menggunakan Oxmetrics untuk 1961 observasi, didapat hasil uji untuk ADRO adalah sebagai berikut: Tabel 4.

Hasil Uji EGARCH ADRO

\begin{tabular}{|c|c|c|c|c|}
\hline Model & Coefficient & Std. Error & t-value & t-prob \\
\hline ARCH (Alpha1) & -0.033296 & 0.24321 & -0.1369 & 0.8911 \\
\hline GARCH (Beta1) & 0.899818 & 0.24321 & 29.21 & 0.0000 \\
\hline EGARCH (Theta1) & -0.067939 & 0.025841 & -2.629 & 0.0086 \\
\hline EGARCH (Theta2) & 0.298561 & 0.086871 & 3.437 & 0.0006 \\
\hline
\end{tabular}

Pada model EGARCH $(0,1,1)$ dapat kita lihat model pada ADRO lebih signifikan dibandingkan ANTM dimana theta 1 ADRO sebesar 0.0086 signifikan ditingkat keyakinan 5\% dan ANTM sebesar 0.0755 signifikan ditingkat keyakinan $10 \%$.

\section{c. Uji GJR}

Berdasarkan hasil uji GJR (1,1) menggunakan Oxmetrics untuk 1965 observasi, didapat hasil ANTM sebagai berikut:

Tabel 5.

Hasil uji GJR $(1,1)$ ANTM

\begin{tabular}{|c|c|c|c|c|}
\hline Model & Coefficient & Std. Error & t-value & t-prob \\
\hline ARCH (Alpha1) & 0.066253 & 0.025304 & 2.618 & 0.0089 \\
\hline GARCH (Beta1) & 0.887604 & 0.020334 & 43.65 & 0.0000 \\
\hline GJR (Gamma1) & 0.077407 & 0.036776 & 2.105 & 0.0354 \\
\hline
\end{tabular}

Berdasarkan hasil uji GJR $(1,1)$ menggunakan Oxmetrics untuk 1965 observasi, didapat hasil ANTM sebagai berikut:

Tabel 6.

Hasil uji GJR $(1,1)$ ADRO

\begin{tabular}{|c|c|c|c|c|}
\hline Model & Coefficient & Std.Error & t-value & t-prob \\
\hline ARCH (Alpha1) & 0.066025 & 0.035277 & 1.872 & 0.0614 \\
\hline GARCH (Beta1) & 0.878663 & 0.045046 & 19.51 & 0.0000 \\
\hline GJR (Gamma1) & 0.068610 & 0.027943 & 2.455 & 0.0142 \\
\hline
\end{tabular}

Dengan model GJR dapat kita lihat bahwa kedua perusahaan memiliki leverage effect dimana tprob gamma masing masing perusahaan mempunyai hasil yang signifikan yaitu GJR $(0,1,1) 0.0354$ untuk ANTM dan GJR $(1,1,1) 0.0142$ untuk ADRO pada tingkat keyakinan 5\%.

\section{d. Pemilihan Model Optimal}

Setelah kita mempunyai ketiga model diatas maka kita akan mencari model yang paling optimum dengan oxmetrics dan menghasilkan hasil analisis sebagai berikut:
Tabel 7.

Log-likelihood ANTM

\begin{tabular}{|c|c|c|c|c|c|}
\hline Model & P & log-likelihood & SC & HQ & AIC \\
\hline G@RCH(1) & 1965 & $4.414,9029$ & $-4,4781$ & $-4,4853$ & $-4,4895$ \\
\hline G@RCH(2) & 1965 & $4.389,7261$ & $-4,4448$ & $-4,4555$ & $-4,4618$ \\
\hline G@RCH(3) & 1965 & $4.427,2757$ & $-4,4868$ & $-4,4958$ & $-4,5010$ \\
\hline
\end{tabular}

Tabel 8.

Log-likelihood ADRO

\begin{tabular}{|c|c|c|c|c|c|}
\hline Model & P & log-likelihood & SC & HQ & AIC \\
\hline G@RCH(1) & 1961 & $4.257,5816$ & $-4,3268$ & $-4,3340$ & $-4,3382$ \\
\hline G@ RCH(2) & 1961 & $4.220,4823$ & $-4,2812$ & $-4,2920$ & $-4,2983$ \\
\hline G@ RCH(3) & 1961 & $4.264,6788$ & $-4,3302$ & $-4,3392$ & $-4,3444$ \\
\hline
\end{tabular}

Dari hasil pemilihan model sebelumnya, didapatkan bahwa GJR/TGARCH adalah model yang paling baik untuk menggambarkan data kedua saham tersebut dimana dapat ditunjukan dengan nilai SC, HQ dan AIC yang paling terkecil, sehingga dapat dibuat persamaan model volatilitasnya:

Model volatilitas ANTM

$\sigma_{t}^{2}=h_{h}=0.146857+0.066253 u_{t-1}^{2}+$

$0.887604 \sigma_{t-1}^{2}+0.077407 u_{t-1}^{2} I_{t-1}+\varepsilon_{t}$

Model volatilitas ADRO

$\sigma_{t}^{2}=h_{h}=0.244703+0.066025 u_{t-1}^{2}+$

$0.878663 \sigma_{t-1}^{2}+0.068610 u_{t-1}^{2} I_{t-1}+\varepsilon_{t}$

Pada paper ini penulis tidak melakukan pemodelan untuk return, karena kami melewatkan proses pemodelan dengan AR, MA, ARMA dan ARIMA, tetapi dengan persamaan volatilitas seharusnya return pada $\mathrm{t}$ dapat di estimasikan dengan menjumlahkan return pada saat $\mathrm{t}-1$ dengan volatilitas pada saat $\mathrm{t}$.

\section{e. Forecast}

Dari hasil pemilihan model, GJR/ TGARCH adalah model yang paling baik untuk menggambarkan data ANTM. Model optimal yang dipilih kemudian dibuat forecast harga saham dan return saham ANTM untuk 40 hari kedepan (out of sample). Berikut adalah plot dari forecast sesuai dengan mean equation yang digunakan: 


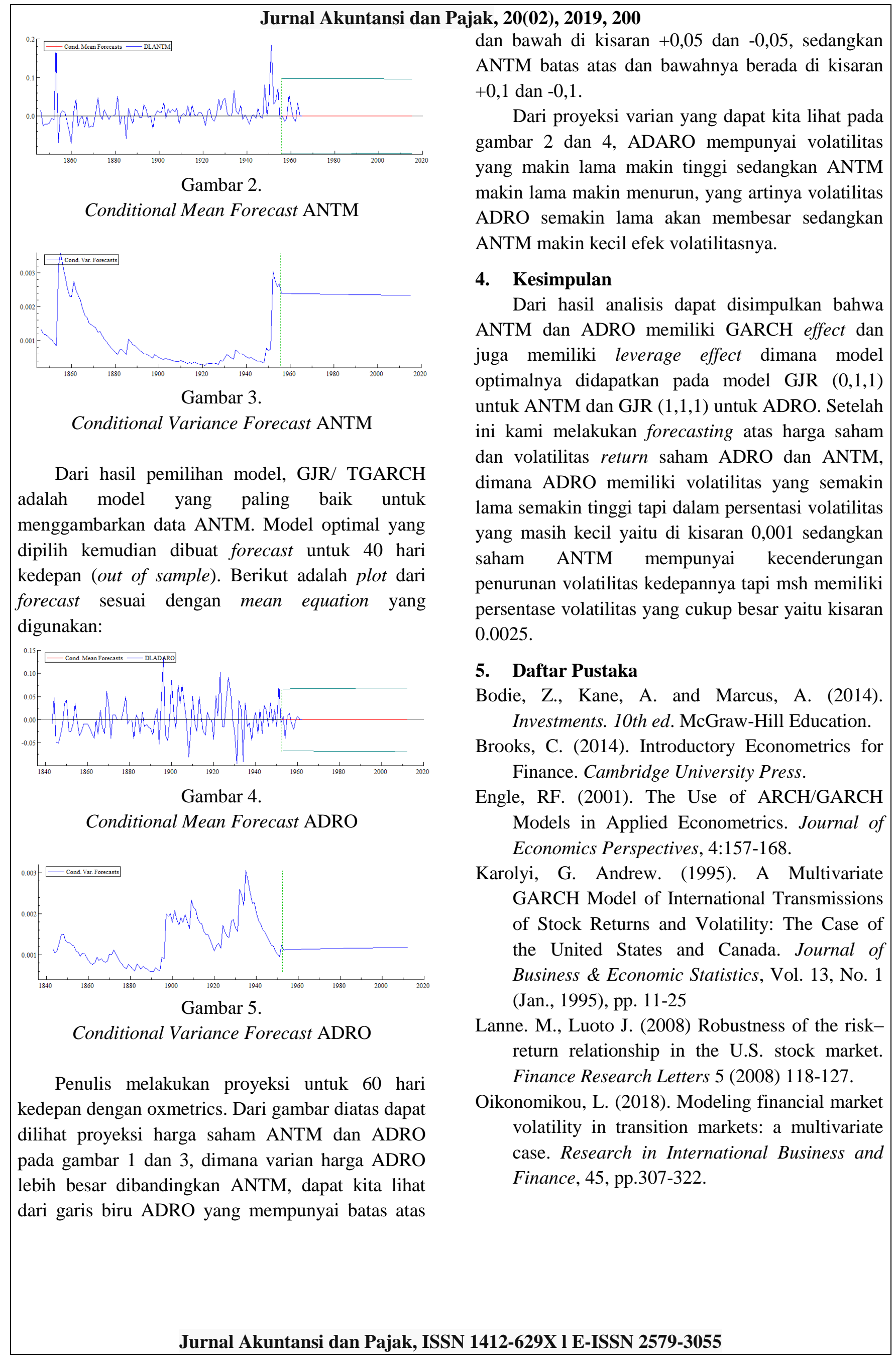

